\title{
Los asentamientos en la ciudad de Barcelona: dificultades y retos de la atención social en el espacio público
}

\author{
María Virginia Matulič Domandzič
}

Unidad de Formación e Investigación (UFR), Trabajo Social, Universidad de Barcelona

mmatulic@ub.edu

\author{
Carles Cabré Vacas \\ PROGESS \\ carles.cabre@progess.com
}

\author{
Albert García Gispert \\ Solucions residencials SORES \\ albert.garcia@sores.cat
}

\begin{abstract}
Mendearen bigarren erdialdetik aurrera sortutako eraldaketa sozial eta ekonomikoek hirietan kokatu zuten asentamendua areagotu zuten. Bere konfigurazioa gure gizarteetako desberdintasun sozialen benetako behatoki gisa aurkezten da. Artikulu honek Bartzelonako Udaleko likidazio irregularreko planaren bulegoan (OPAI) 20192020 aldian egindako ikerketa kualitatiboaren emaitzak erakusten ditu, espazio publikoan gizartearreta eta bere politikak ardatz hartuta. Emaitzek ondorioztatzen dute profesionalek garatzen duten arreta soziala laguntza sozioedukatibo intentsiboan oinarritzen dela. Egoeren konplexutasunak kulturarteko eta komunitateko ikuspegia eskatzen du, inplikatutako eragile sozial guztien artean sareak barne hartzen dituena. Erronka nagusien artean, artatutako pertsonek aurkeztutako bizitegibazterketa prozesu desberdinak bideratzen dituzten politika publikoak garatzen dira.
\end{abstract}

\section{GAKO-HITZAK:}

Asentamenduak, arreta soziala, laguntza sozioedukatiboa, espazio publikoa, Bartzelonako hiria.
Las transformaciones sociales y económicas producidas a partir de la segunda mitad del siglo XX incrementaron la presencia de los asentamientos en las ciudades. Su configuración se presenta como un verdadero observatorio de las desigualdades sociales en nuestras sociedades. El presente artículo muestra los resultados de la investigación cualitativa realizada en el periodo 2019-2020 en la Oficina del Plan de Asentamientos Irregulares (OPAI) del Ayuntamiento de Barcelona, centrando la mirada en la atención social en el espacio público y en sus políticas. Los resultados concluyen que la atención social desarrollada por los profesionales se basa en un acompañamiento socioeducativo de carácter intensivo. La complejidad que presentan las situaciones requiere de un enfoque intercultural y comunitario que incorpore un trabajo en red entre todos los agentes sociales implicados. Como retos principales, se destacan el desarrollo de políticas públicas que atiendan los diversos procesos de exclusión residencial que presentan las personas atendidas.

\section{Palabras Clave:}

Asentamientos, atención social, acompañamiento socioeducativo, espacio público, ciudad de Barcelona. 


\section{Cambios y representaciones del espacio público}

El espacio público representa el lugar donde se producen las interacciones y las relaciones sociales de una comunidad. Es en estos espacios donde las personas realizan actividades funcionales y rituales que las unen a una comunidad (Carr et al., 1992: 6). Un universo complejo y diverso donde se produce la representación de la sociedad en la que se inscribe la ciudad y donde se articulan diversas alteridades que no están exentas de conflictos (Velázquez, 2007: 20).

A finales de la década de los setenta, el capitalismo había instrumentalizado el espacio público produciendo profundas desigualdades que habían generado importantes transformaciones, tanto en el acceso como en el uso de este espacio. Autores como Lefebvre (1969) ya planteaban el derecho a la ciudad como una alternativa de resistencia frente a las propuestas promovidas por los Estados modernos. La reivindicación de este derecho implicaba promover espacios igualitarios donde los ciudadanos pudieran articular diversos intercambios y tejer variadas complicidades. Este derecho a la ciudad se encuentra hoy restringido y rodeado de conflictos (Harvey, 2003).

El uso del espacio público se ha ido transformando y sus cambios se vinculan a varias dimensiones (políticas, sociales, económicas y culturales) que impactan de forma directa a los territorios. Autores como Soja (1996) reconocen que la construcción social del espacio público en el capitalismo es un proceso en el que intervienen multitud de fuerzas, donde toman importancia las dimensiones culturales y políticas. En esta línea, Delgado y Malet (2007) destacan la connotación ideológica que rodea este espacio como reproductor de las desigualdades sociales en nuestras sociedades.

Las ciudades europeas inician en los años ochenta importantes cambios y transformaciones que afectarán a la configuración y los usos del espacio público. Entre las más importantes destacan las vinculadas a las políticas de regeneración urbana, que tenían como objetivo reducir la concentración de la pobreza en varias zonas de las ciudades. Barcelona lidera en esta época varios planes de recuperación de áreas degradadas, tanto en zonas periféricas como céntricas de la ciudad. Según Tapada y Arbaci (2011) la implementación de estas actuaciones fomentará procesos de gentrificación en zonas emblemáticas de la ciudad, produciendo procesos de exclusión y segregación urbana.

Barcelona inicia en la década de los noventa (con motivo de los Juegos Olímpicos) un proceso de transformación que configurará la ciudad en el llamado Modelo Barcelona. A través de esta propuesta urbana de inspiración neoliberal se producirá una serie de actuaciones centradas en favorecer las demandas del mercado global por encima de las necesidades sociales de la población en estos espacios. Según Delgado y Malet (2007: 6o), la cuestión urbana ha sufrido importantes transformaciones donde la ideología dominante se legitima a través de diversas estrategias, la exclusión de todo aquello que resulte problemático o discordante con el modelo de ciudad que se pretendía promocionar.

La Administración Pública es la encargada de la regulación y la gestión del espacio público, fijando a través de sus normativas la configuración y condiciones de uso de este espacio para todos los ciudadanos. En este sentido, la ciudad de Barcelona ha sido pionera en la regulación de este espacio a través de la Ordenanza de medidas para fomentar y garantizar la convivencia ciudadana en el espacio público de Barcelona (BOP, 2006). Según diversos autores (Brenner, Peck y Throdore, 2009; Delgado y Malet, 2007), estas regulaciones tienen la función de convertirse en medidas de vigilancia y control de las poblaciones excluidas y con menos capacidad de consumo. En este sentido, las personas y grupos que desarrollan su vida en este espacio son considerados amenazantes y peligrosos para la convivencia ciudadana (Palleres, 2004). Autores como Ferreres y Fernández (2018) afirman que estas medidas se vinculan a una gestión neoliberal del sinhogarismo que tiene la función de penalizar y criminalizar a las personas que se encuentran transitando por diversos procesos de exclusión social en la ciudad.

La dimensión espacial se convierte en un elemento esencial para la comprensión del sinhogarismo, ya que las personas en situación de calle desarrollan su cotidianidad en un espacio público. Esta apropiación del espacio urbano genera incomodidad y rechazo, ya que no solo es simbólica, sino también física - principalmente, a través de la conformación del espacio individual-, y es en este lugar donde se manifiesta claramente el rechazo que produce la presencia de desconocidos o de extraños en el espacio público (Palleres, 2004).

Varios autores coinciden en afirmar que la movilidad es una de las principales particularidades de las personas sin hogar (Muñoz et al., 2003; Sánchez Morales, 2010; Cabrera, 1998). Según Bachiller, el resultado de la exclusión social que afecta a estas personas se expresa a través de un proceso de movilidad forzada. Esta estrategia se materializa por medio de la presión que realizan determinados agentes o fuerzas de seguridad, a través de la ubicación de los recursos sociales en determinadas zonas de la ciudad o en las políticas de reconversión urbana que se llevan a cabo en grandes ciudades (Bachiller, 2009).

El Ayuntamiento de Barcelona, a través del Departamento de Atención a Personas sin Hogar y de intervención en el espacio público, del Instituto Municipal de Servicios Sociales (IMSS), es el responsable de articular políticas sociales dirigidas a las personas que se encuentran en situación de sin techo y sin hogar en la ciudad. El ayuntamiento cuenta con una información detallada de las 
personas que duermen en las calles de la ciudad. Recuentos mensuales, mapas de localización y memorias anuales facilitan un constante registro de la ubicación y movilidad de las personas y grupos en todo el territorio. A partir del año 2013 se produce un cambio organizativo y el Servicio de Inserción Social (SIS) que estaba gestionado por este departamento pasa a depender de lo que es ahora el Departamento de Servicio de Urgencias y Emergencias Sociales y de Intervención en el Espacio Público. Sin embargo, desde el año 2018 se empieza a valorar la idea de fusionar la oficina con el Servicio de Inserción Social de Medio Abierto (SISMO). Fusión que está prevista materializarse a inicios del año 2021.

Este cambio nos informa de la importancia que tiene la gestión del espacio público en las políticas sociales orientadas a las temáticas relacionadas con la exclusión social en la ciudad de Barcelona.

\section{Los asentamientos en la ciudad de Barcelona: una aproximación histórica}

Los asentamientos son un reflejo de los cambios sociales y económicos imperantes en nuestras sociedades. Según el Diagnóstico 2019, unas 498 personas viven en asentamientos en la ciudad de Barcelona (De Inés et al., 2019). El número de personas se ha ido reduciendo desde 2011, en el que había llegado a 695 personas. De los diversos factores que contribuyeron al crecimiento del fenómeno de los asentamientos en la ciudad de Barcelona, sobre todo entre la población inmigrante, cabe destacar los siguientes:

1. El impacto de la crisis económica sobre la tasa de paro del colectivo inmigrante, que dobla la media.

2. El alto número de solares y naves industriales abandonadas.

3. Los traslados ordenados por el Estado de personas de origen subsahariano en situación documental irregular procedentes de Canarias, Ceuta y Melilla.

4. La recogida de chatarra como una de las principales opciones de actividad económica informal para muchas personas en situación de exclusión social.

5. El rechazo de las ofertas de los servicios estándar de inclusión social de la ciudad por parte de la mayor parte de los residentes en los asentamientos.

Todo ello incidió en un crecimiento significativo del número de asentamientos en la ciudad. Si tradicionalmente se trataba de asentamientos de familias gitanas galaicoportuguesas o rumanas, entre 2011 y 2013 aparecen asentamientos de personas de origen subsahariano y de otras nacionalidades.

El Servicio de Inserción Social (SIS) inicia el trabajo con asentamientos conformados por familias de origen galaicoportugués en el año 1994, cuando estas familias tenían un carácter eminentemente itinerante y hacían estancias temporales en la ciudad entre octubre y abril. La acción del SIS se coordina con los servicios sociales de los territorios donde se asentaban estas familias, eminentemente el distrito de Sant Martí. Sin embargo, la intervención quedaba interrumpida por el carácter itinerante de la población diana. A mediados de la primera década del siglo XXI, estas familias perdieron su carácter itinerante y se establecieron en diferentes territorios de la ciudad de manera estable, aprovechando los espacios de uso privativo en desuso. Es entonces cuando la intervención con estas familias se asume desde el Servicio de Atención Social a Personas Itinerantes (SASPI) ${ }^{1}$, dadas las características específicas que las diferenciaban de los perfiles atendidos habitualmente por el SIS.

Los antiguos equipos de SASPI (ahora Servicio de Intervención Social de Familias con Menores, SISFAM) se dirigen a mejorar las condiciones de vida de las familias con niños a cargo, que viven en asentamientos o cualquier tipo de infravivienda en la ciudad de Barcelona. Los objetivos del servicio orientados a las familias son conseguir que encuentren alternativas de inserción social y laboral que les permitan cambiar de estilo de vida y obtener estabilidad, fomentar el seguimiento de itinerarios formativos y laborales de los adultos para la búsqueda de ingresos estables que les permitan cubrir las necesidades básicas, y velar por la convivencia y la cohesión social en torno a los asentamientos a través del trabajo social con las familias en el espacio público. Este servicio también se dirige a la mejora de las situaciones de los niños en edad escolar, garantizando su escolarización y el seguimiento médico y pediátrico ${ }^{2}$.

En el año 2003 los equipos del SIS detectaron, sobre todo en el distrito de Sants-Montjuïc, un nuevo conjunto de familias Rom, originarias de Rumania, que destacan como un fenómeno emergente y en alza. La intervención con estas familias, que ocupaban el espacio público y zonas de uso privativo, la efectuó en primera instancia el SIS, hasta que la atención integral de las familias rumanas asentadas pasó al SASPI.

Durante el año 2003 tuvo lugar el establecimiento de grupos de personas en situación administrativa irregular en los antiguos cuarteles de Sant Andreu, ocupados sobre todo por personas solas de varias nacionalidades, entre las que había un importante porcentaje de personas provenientes de países subsaharianos. El desmantelamiento de este gran asentamiento, que llegó a tener más de quinientos individuos, dispersó por toda la ciudad una multitud

${ }^{1}$ Actualmente el Servicio de Inserción Social de Familias con Menores a su Cargo.

2 Para más información: 〈https://ajuntament.barcelona.cat/ prevencio/ca/servei-inserci\%C3\%B3-social-fam\%C3\%ADlies-romsisfarom>. 


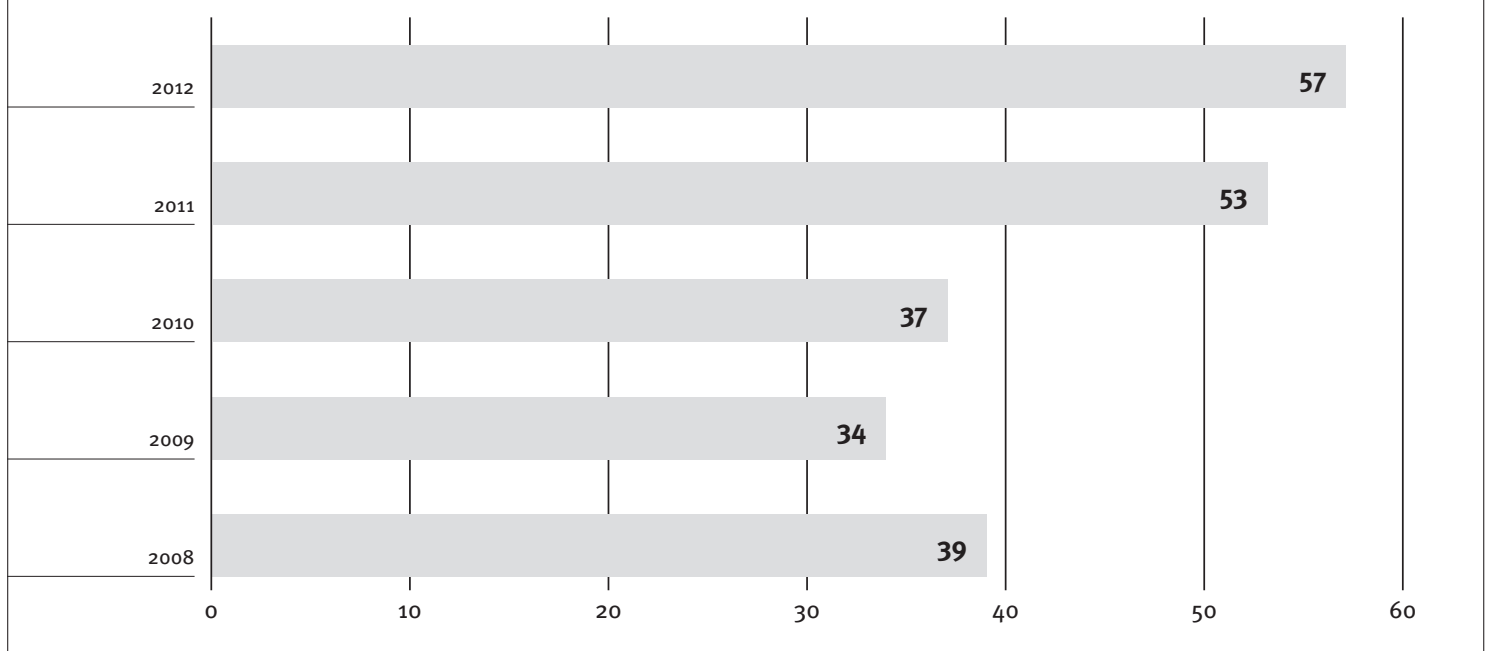

Fuente: Servicio de Inserción social, Ayuntamiento de Barcelona.

Gráfico 2. Personas contabilizadas en asentamientos en la ciudad de Barcelona por el Servicio de Inserción Social

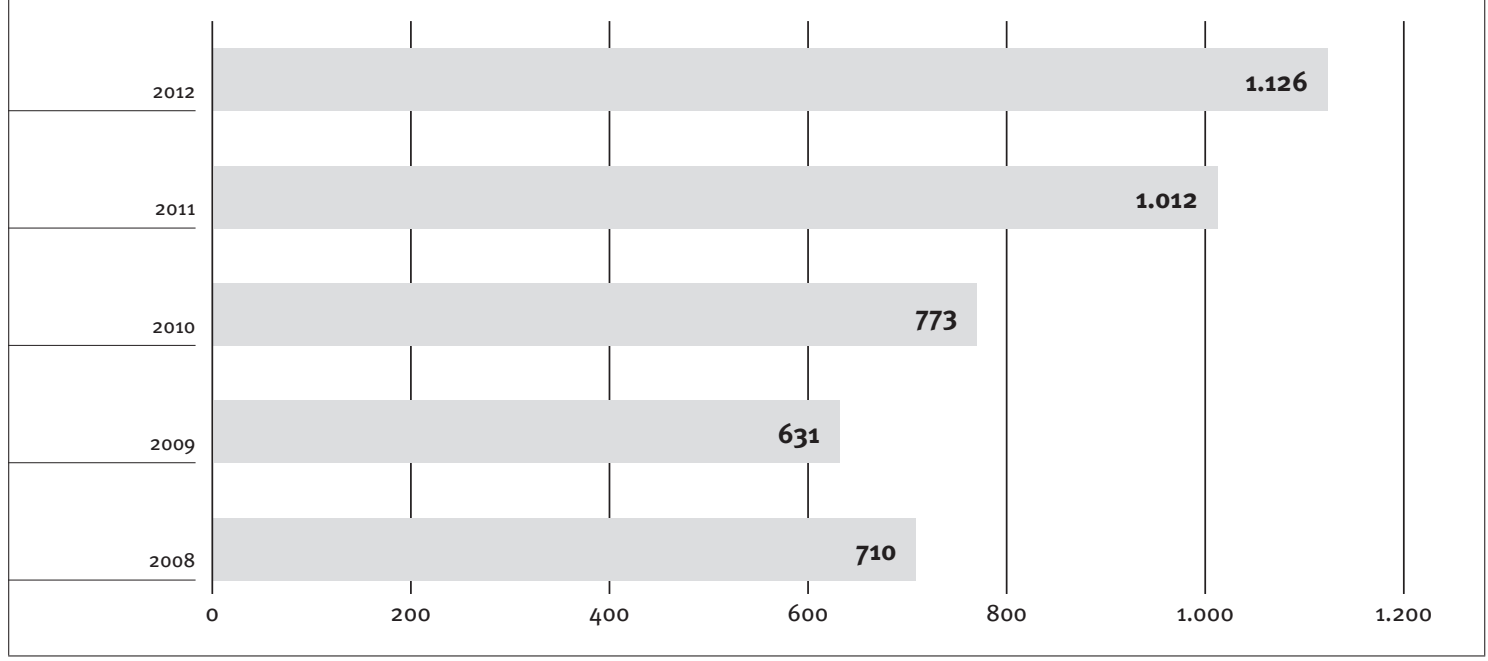

Fuente: Servicio de Inserción social, Ayuntamiento de Barcelona.

de personas que se encontraban en situación administrativa irregular y sin posibilidades de acceder al mercado de trabajo. Aunque los dispositivos de alojamiento y atención social fueron desplegados por el Ayuntamiento de Barcelona, en colaboración con la Cruz Roja, gran parte de las personas atendidas quedaron fuera de los circuitos de atención.

A falta de un servicio especializado que cuantifique con exactitud el fenómeno, desde el Ayuntamiento de Barcelona se encarga esta tarea al SIS, que inicia la recogida sistemática de datos en el año asentamientos y de las personas contabilizadas en estos espacios en la ciudad en los últimos cinco años, hasta la creación del OPAl en el año 2013 (ver Gráfico 1 y Gráfico 2).

En el año 2012, desde el Departamento de Atención a Personas Vulnerables, órgano dependiente de la
Dirección de Familia y Servicios Sociales del Área de Calidad de Vida, Igualdad y Deportes, se definieron las diferentes intervenciones que los equipos de SASPI y SIS realizaban en espacios de uso privativo, considerando las ocupaciones de espacios privados y definiendo los asentamientos en ellos como "la pernoctación de grupos de personas en naves, fábricas y otras edificaciones abandonadas con estructuras de alojamiento precario (barracas, caravanas, camiones, etc.”.

Igualmente, se definieron las diferentes tipologías que se detectaban habitualmente a los asentamientos:

1. Personas gitanas galaicoportuguesas (itinerantes).

2. Personas gitanas rumanas.

3. Personas africanas (senegalesas, guineanas y procedentes de otros países subsaharianos). 
4. Personas de varias nacionalidades diferentes a las anteriores.

Aunque el Ayuntamiento de Barcelona ya contaba con un servicio específico, el SASPI, para atender a las familias asentadas de origen galaicoportugués y rumano, así como con un servicio de atención específica a personas sin techo, el SIS, que también se encargaba de la detección y cuantificación de los asentamientos, ante el aumento y las nuevas situaciones detectadas se planteó la necesidad de diseñar y ejecutar un plan de intervención específico de asentamientos. Con esta doble finalidad y la voluntad de centralizar las funciones de los diferentes servicios que ya trabajaban hacia los asentamientos se creó, en enero de 2013, la Oficina del Plan de Asentamientos Irregulares (OPAI), dentro del Departamento de Acción Comunitaria del Área de Calidad de Vida, Igualdad y Deportes.

En el mes de marzo de 2012 el gobierno municipal adquirió, en las comisiones plenarias de Calidad de Vida, Igualdad y Deportes y de Hábitat Urbano, el compromiso de impulsar un plan integral de asentamientos irregulares. Cinco fueron los fines que persiguió este plan en su inicio: 1. Velar por la dignidad y seguridad de las personas. 2. Garantizar la convivencia cívica, vecinal y social. 3. Tender a la erradicación del fenómeno de asentamientos, teniendo bien presente su complejidad. 4. Trabajar las posibles salidas, caso por caso, de todos ellos, buscando el conjunto de soluciones que deben hacerlo posible. Se plantea un proceso con acciones a corto, medio y largo plazo en el que el Ayuntamiento de Barcelona extremará todas sus capacidades. 5. Implicar a todas las Administraciones involucradas; es fundamental papel del Estado español, que es la administración competente en la regulación de flujos, control de fronteras y documentación de los inmigrantes.

En el marco de este plan se trabajó un concepto básico de asentamiento, que quedó definido como "pernoctas que se realizan básicamente a través de la ocupación de espacios privados o públicos en naves (fábricas o edificaciones abandonadas) solares con estructuras de alojamiento precario (barracas, caravanas, camiones-vivienda, etc.) que se mantienen en el tiempo".

La misión del proyecto contempló tres momentos:

- Fase 1. Redactar un informe de diagnóstico y de plan de acción, mediante la creación de una task force multisectorial, capaz de involucrar a toda la administración del Ayuntamiento de Barcelona.

- Fase 2. Diseñar e implantar un plan de innovación social que tenga como objetivo aportar soluciones a la problemática de los asentamientos irregulares en Barcelona.

- Fase 3. Coordinar el Plan de Asentamientos Irregulares con los objetivos de mejora de la calidad de vida de la ciudad, con énfasis en los grupos sociales en condición de pobreza y en la consolidación de una ciudad eficiente, segura, competitiva y socialmente justa.

La necesidad de coordinar un Plan de Asentamientos Irregulares hacía necesario que interactuaran diversos actores, que se recogen la Figura 1.

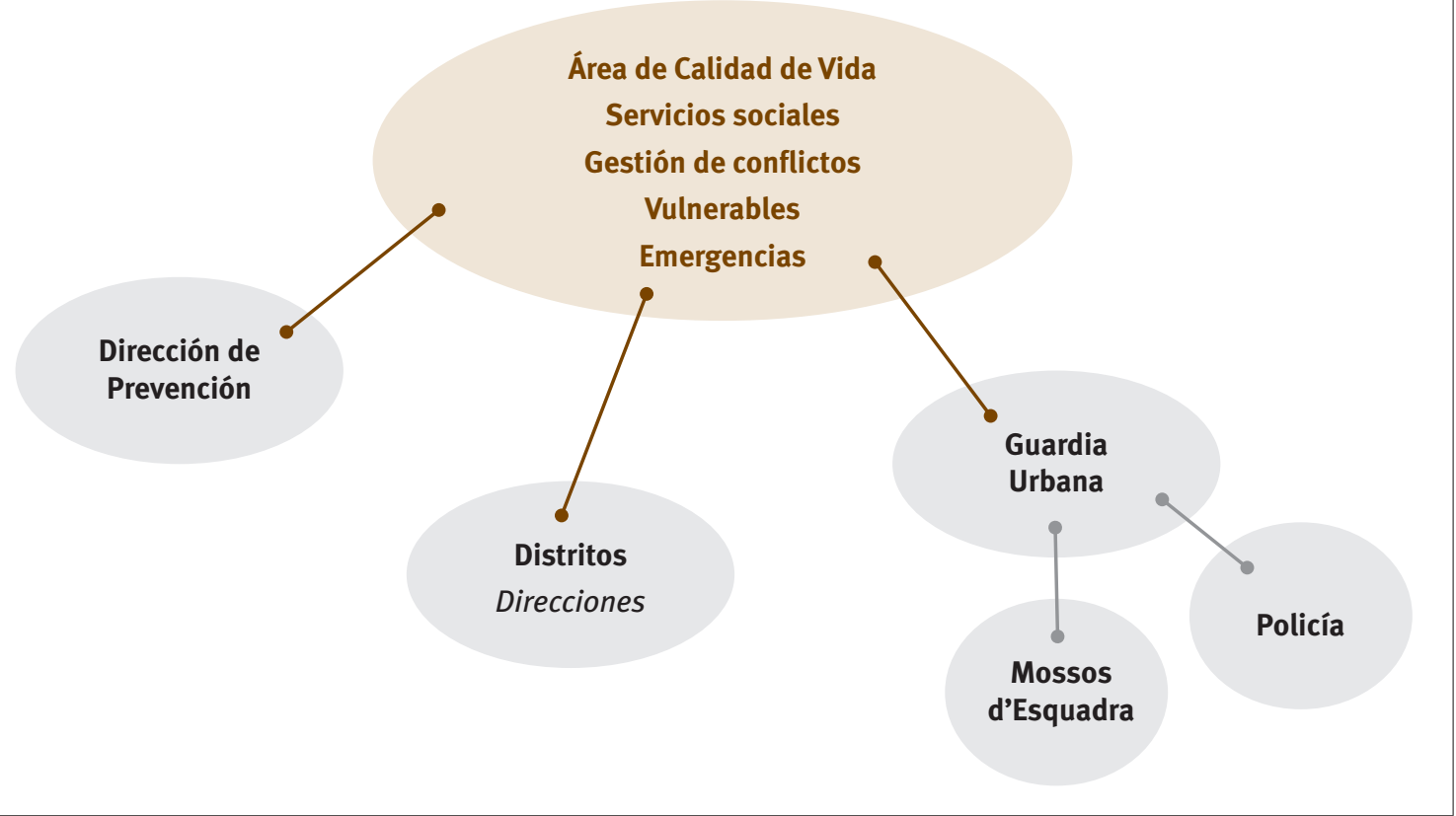

Fuente: Comisión de Hábitat Urbano, Plan de Asentamientos Irregulares, octubre 2012. 
Atendiendo al conocimiento que había de los diversos colectivos, sus necesidades y las posibilidades de actuación se definieron, de manera general, tres tipologías bastante coincidentes con las que ya trabajaban SIS y SASPI:

1. Itinerantes (galaicoportugueses).

2. Rumanos.

3. Otras nacionalidades (mayoritariamente subsaharianos).

El abordaje de cada uno de estos colectivos requería atenciones diferenciadas, dado que concurrían circunstancias que requerían cuidados específicos. Por ejemplo, la presencia de menores en los núcleos familiares de itinerantes y rumanos y la situación de irregularidad administrativa de la mayor parte de los subsaharianos.

La propuesta de medidas para la implementación del Plan de Asentamientos Irregulares fue principalmente la creación de la OPAI para definir las medidas y acciones específicas, además de asegurar su implementación, priorizando y asegurando su seguimiento con indicadores adecuados, calendario y presupuesto asignado.

\subsection{Definición y características de los asentamientos irregulares o establecimientos informales}

Un asentamiento irregular o infravivienda es un lugar donde se establece una persona o una comunidad que está fuera de las normas establecidas por las autoridades encargadas del ordenamiento urbano. Los asientos pueden categorizarse de diversas formas, ya sea por su tamaño, su tipo de actividad productiva o sus características geoadministrativas: ciudades, colonias, municipios, pueblos, subdivisiones, villas, etc. Pueden existir varios tipos de asentamientos de acuerdo con las diferentes leyes de ordenamiento territorial y podemos dividirlos en:

- Asientos formales o regulares.

- Asentamientos informales o irregulares.

Un establecimiento formal o asentamiento regular forma parte del esquema del planteamiento territorial de una ciudad. Un asentamiento irregular está fuera del esquema de planificación urbana o territorial. El asentamiento irregular o informal es un lugar donde se establece un conjunto de personas, grupo humano, o comunidad, que está fuera del margen de los reglamentos que rigen el uso y ordenación territorial que establecen las autoridades encargadas del ordenamiento urbano.

Desde el equipo de detección del Servicio de Inserción Social se ha definido el asentamiento como el agrupamiento en un espacio amplio de un conjunto numeroso de personas que constituye un sistema de vida comunitaria más o menos organizada en función de los lazos de parentesco y/o afinidades de sus integrantes.
Sin embargo, recientemente el ayuntamiento considera asentamiento como aquel espacio (no calle, parque, plaza, pasaje, etc.), nave industrial o solar, de titularidad pública o privada, con estructuras precarias y no preparadas en su origen para residir, que se mantiene ocupado en el tiempo como residencia continuada por una persona 0 por un colectivo. Aparte del uso de vivienda, se da actividad (almacenamiento, selección, compraventa, etc.) alrededor de desechos diversos (chatarra, papel y cartón, electrodomésticos, etc.). Esta definición basada en el tipo de espacio unido a la residencia continuada no resulta suficientemente inclusiva para abarcar las diferentes situaciones que se observan alrededor de los asentamientos. Es por ello que hay que ampliar el marco de definición incorporando las dinámicas de asentamientos en el espacio público. Así, se incluyen otras infraviviendas con dinámica de asentamiento y las dinámicas de asentamiento en el espacio público. Se considera que una infravivienda (locales ocupados, edificios, espacio público) tiene dinámica de asentamiento cuando conserva las características que se dan en los asentamientos irregulares en naves y solares: establecimiento espontáneo de un grupo de personas o colectivo en espacios no destinados a vivienda en la planificación urbana y/o territorial, instalación de estructuras precarias en condiciones deficitarias para vivir y pernoctar, y como espacio donde el grupo de personas se organiza para hacer frente a las propias necesidades, a través de actividades de subsistencia - recogida, manipulación y venta de chatarra, cartón, mendigar, etc.- (Generalitat de Catalunya, 2020).

Los establecimientos irregulares en general son densos asentamientos que abarcan a comunidades 0 individuos, albergadas en viviendas autoconstruidas bajo deficientes condiciones de vida. Toman forma de establecimientos espontáneos sin reconocimiento ni derechos legales, expandiendo los bordes de las ciudades en terrenos marginados que están dentro de los límites de las zonas urbanas.

Son característicos de los países en vías de desarrollo. En países desarrollados se encuentran en zonas con altos índices de pobreza, en territorios habitados por comunidades de inmigrantes o minorías étnicas, y en territorios en vías de planificación urbanística o de reordenación. Típicamente son el producto de una necesidad urgente de obtención de vivienda de las comunidades urbanas con escasos recursos económicos. Como tales, se caracterizan por ciertas condiciones:

1. Una densa proliferación de viviendas elaboradas con diversos materiales reciclados.

2. Degradación ambiental causada en el ecosistema local.

3. Severos problemas sociales.

Se generan cuando la Administración y las autoridades de desarrollo urbano no pueden tratar las necesidades de una determinada comunidad o 
cuando grupos de personas necesitan un lugar donde vivir, pero no disponen de los recursos económicos necesarios para poder adquirir una vivienda regular. Estas áreas de asentamiento se caracterizan por poseer un nivel muy rápido de crecimiento, no estructurado y no planeado. A escala global, los asentamientos irregulares son un problema significativo, especialmente en los países del Tercer Mundo. Dentro de estos asentamientos es fácil la formación de grupos de afines, y a menudo sirven como escondites de bandas de delincuentes. Los robos, hurtos y violencia de todo tipo se dan más a menudo en estos lugares por la marginalidad en la que viven. El consumo y venta de drogas tienen en estos lugares su epicentro.

Un informe de la comisión de la seguridad social de las Naciones Unidas de 1986 indicó que entre un $30 \%$ y un $60 \%$ de los residentes de las ciudades más grandes de los países subdesarrollados viven en asentamientos irregulares.

Normalmente los asentamientos irregulares tienen una estructura organizacional definida, que es encabezada por los líderes comunitarios. Esta organización es una respuesta de protección ante las presiones de las autoridades locales, que generalmente trabajan para desalojar estos asentamientos. La organización de un asentamiento irregular se lleva a cabo mediante la generación de una relación de solidaridad entre sus vecinos (Barry y Mayson, 2000).

Los establecimientos irregulares son sistemas sociales dinámicos complejos que experimentan un cambio continuo. Al ocupar la tierra irregularmente, los residentes están a menudo preparados para evadir la ley con la esperanza de mejorar su posición económica. Típicamente, la dinámica política y social interna se caracteriza por la solidaridad y/o la confrontación. Sin embargo, el conflicto interno es inherente a la relación de la comunidad y los agentes externos, como las autoridades y los residentes circundantes. Las autoridades, en general, adoptan una actitud pasiva respecto a estas zonas degradadas, interviniendo solo cuando su crecimiento genera inquietud social, desórdenes, disturbios o crimen organizado. La disparidad visible entre los asentamientos irregulares y las áreas circundantes puede llevar a tensiones sociales y generar dificultades entre la población residente y los responsables políticos.

Los mecanismos de solidaridad entre los diferentes grupos y personas que conforman los asentamientos se activa durante las negociaciones con las autoridades, pero las disputas internas son frecuentes durante la implementación de los programas de reordenación emprendidos por las autoridades (realojos, ayudas institucionales, etc.) siendo, sin embargo, también frecuentes las disputas internas por el control de los mejores accesos y parcelas y otros de carácter territorial, étnico, de afinidad de grupo o personal (Barry y Mayson, 2000).
Para un agente externo, es muy difícil intervenir en los establecimientos irregulares con los objetivos de mejorarlos o procurar que las condiciones físicas e higiénicas mejoren y la justicia social prevalezcan. Las relaciones con las autoridades tienden a ser irregulares y tienden a procurarse ayuda institucional inmediata sin contraprestación. Debido a ello, es difícil que las instituciones formales de ordenamiento territorial puedan hacer repartos equitativos.

Debido a la complejidad de esta situación (diversidad de integrantes y de intereses, formas diversas de procurarse la subsistencia, competencia territorial, etc.), muchos proyectos de mejoras no logran alcanzar los resultados deseados por las autoridades. En particular, muchos observadores critican proyectos que entregan arrendamientos individuales, especialmente propiedad libre de impuestos. Sin embargo, también existen problemas asociados con el uso de formas comunales de arrendamiento (Fourie, 1993), ya que estas soluciones no se ajustan por igual a todos los integrantes de los asentamientos.

El trazo de un asentamiento informal en general es de forma irregular. Normalmente este tipo de asentamientos no disponen en un inicio de una mínima infraestructura: agua potable, drenaje, electricidad o teléfono. Frecuentemente se localizan en zonas de riesgo y sujetos a la degradación ambiental. Se complica la implementación de los servicios básicos por su falta de planificación y diseño urbano, además de por su acelerado crecimiento. De esta forma, los habitantes de los asentamientos irregulares tienen más riesgos de contraer enfermedades debido a sus niveles de pobreza y la influencia negativa del entorno donde residen. Con el transcurso del tiempo el emplazamiento se va dotando de unos servicios mínimos mediante la autoconstrucción, la cooperación comunitaria y el aprovechamiento ilícito de redes comunitarias de abastecimiento.

Los residentes se encuentran en un estado permanente de inseguridad legal y precariedad, ya que viven en terrenos sin el consentimiento de sus propietarios, y están sujetos a amenazas de desalojo y a la negación de servicios vitales como agua potable, recogida de basuras, drenaje pluvial, pavimentación de calles e iluminación, entre otros. Igualmente, sus habitantes no tienen suficiente instrucción y, por tanto, no es común que desarrollen actividades económicas formales, viéndose abocados a formas de obtención de ingresos irregulares y/o ilegales.

Pese a que los asentamientos irregulares parecen tener un origen espontáneo, lejos de serlo obedecen a una lógica de producción de suelo para los pobres. No son espontáneos en su aparición, ya que tardan años en consolidarse, ni en su empleo, ya que en la inmensa mayoría de casos responden a una lógica propia de organización y distribución del espacio. 


\section{La intervención en el espacio público}

El Ayuntamiento de Barcelona crea en la década de los noventa del siglo XX el Servicio de Inserción (SIS). Estos equipos de proximidad atienden a personas y familias que se encuentren en situación de desarraigo social. Siguiendo la tipología ETHOS 3 , las personas objeto de atención se encuentran en la categoría de sin techo (personas viviendo en situación de calle y personas que pasan la noche en albergues para personas sin techo) y vivienda inadecuada (personas que viven en estructuras no convencionales y temporales y en viviendas insalubres). Los equipos de detección de medio abierto actúan en todos los barrios de la ciudad.

El servicio está organizado a través de varios equipos profesionales: medio abierto, equipos de primera acogida y tratamiento que están formados por trabajadores/as sociales, educadores/as sociales y psicólogos/as. Su intervención se orienta a los aspectos relacionados con la mejora de hábitos, la información, orientación y seguimiento de los diversos aspectos relacionados con las dificultades de las personas sin hogar de la ciudad. Los profesionales vinculan a estas personas a los servicios adecuados y realizan un seguimiento de su proceso de inserción. Y los equipos de tratamiento son los responsables de facilitar el desarrollo de los procesos personales de inserción y rehabilitación de las personas atendidas desde un modelo proactivo.

Desde el SIS se despliegan dos ejes de intervención: la detección y seguimiento social de las personas que se encuentran en situación de calle y la gestión del impacto en el espacio público. Desde este servicio se gestionan las quejas de vecinos referidas a las dinámicas de las personas en el espacio público, se coordina de forma continuada con los servicios de seguridad (Guardia Urbana y Mossos d’Esquadra), así como también servicios de tipo sanitario (entre los que se encuentran el equipo especializado en salud mental para personas sin techo) y social (el Centro de Urgencias y Emergencias Sociales de Barcelona).

Su metodología de intervención se basa en un modelo proactivo caracterizado por las prospecciones que realizan en diferentes franjas horarias (mañana y noche) y la coordinación con diferentes agentes del territorio (Guardia Urbana, servicios técnicos, asociaciones de vecinos y comerciantes, etc.). También tiene la función de gestionar el impacto provocado por la presencia de personas sin techo en el espacio público y de dar respuesta a las diferentes demandas efectuadas por la ciudadanía al respecto de esta problemática.

Las bases fundamentales en la que se articulan las intervenciones sociales con personas sin hogar son la proximidad y el acompañamiento social. Roche

${ }^{3}$ El índice European Typology of Homelessness and Housing Exclusion (ETHOS) describe los diversos tipos de exclusión residencial en la que se pueden encontrar las persones y familias.
(2007) entiende la proximidad como una forma de intervención proactiva y construida conjuntamente con y lo más cerca posible de la persona. Es decir, desde esta mirada centrada en la persona se construye la relación de ayuda teniendo en cuenta los elementos fundamentales que están incidiendo en su proceso vital y en su entorno habitual.

La intervención de proximidad se asocia en España al trabajo de calle o del medio abierto que se aplica para trabajar diversas situaciones de dificultad en los entornos más habituales donde se encuentran las personas o grupos atendidos. Para Funes (2001), la calle se convierte en un espacio educativo donde se pueden encontrar con los iguales y pueden ejercer formas de ser propias de ellos mismos. A través de esta forma de intervención se reconocen las posibilidades educativas en el medio natural y en las personas atendidas. Esta práctica estuvo muy extendida durante la década de los ochenta vinculada a los servicios sociales de atención primaria (educadores de calle), o varias entidades que atendían a adolescentes y jóvenes en diversas situaciones de exclusión social (relacionados con temas educativos, legales, culturales o sanitarios).

La intervención con personas sin hogar incorpora esta perspectiva de proximidad aplicando la metodología socioeducativa en los procesos de acompañamiento social. Según el Diccionario de Servicios Sociales de Cataluña, “la intervención socioeducativa es la acción educativa intencional y sistemática en el ámbito social con población con necesidades específicas" (Colomer y Rustullet, 2010: 95). A través de las actuaciones se requiere por parte de los profesionales que la realizan una actitud proactiva que permita la vinculación de las personas a servicios o recursos de la XAPSLL en primer lugar, y posteriormente a otros dispositivos del sistema de bienestar.

\subsection{Oficina del Plan de Asentamientos Irregulares}

A partir del año 2013, se crea una oficina especializada en los asentamientos de la ciudad, la Oficina del Plan de Asentamientos Irregulares (OPAI). Con el paso del tiempo, este servicio se estructura de la forma que muestra la Figura 2.

\subsubsection{Unidades de atención y servicios de apoyo}

El OPAI se estructura en tres unidades operativas y cuatro servicios de apoyo. Las tres unidades operativas son las siguientes:

1. La unidad de coordinación. Esta figura es la responsable de dirigir y coordinar los profesionales de la oficina y de la organización y coordinación de las actuaciones del servicio.

2. La unidad de prospección y atención educativa. Responsable de la localización, recuento, análisis y clasificación de los asentamientos; de vincular a las personas contactadas al servicio 
Oficina del Plan de Asentamiento Irregulares

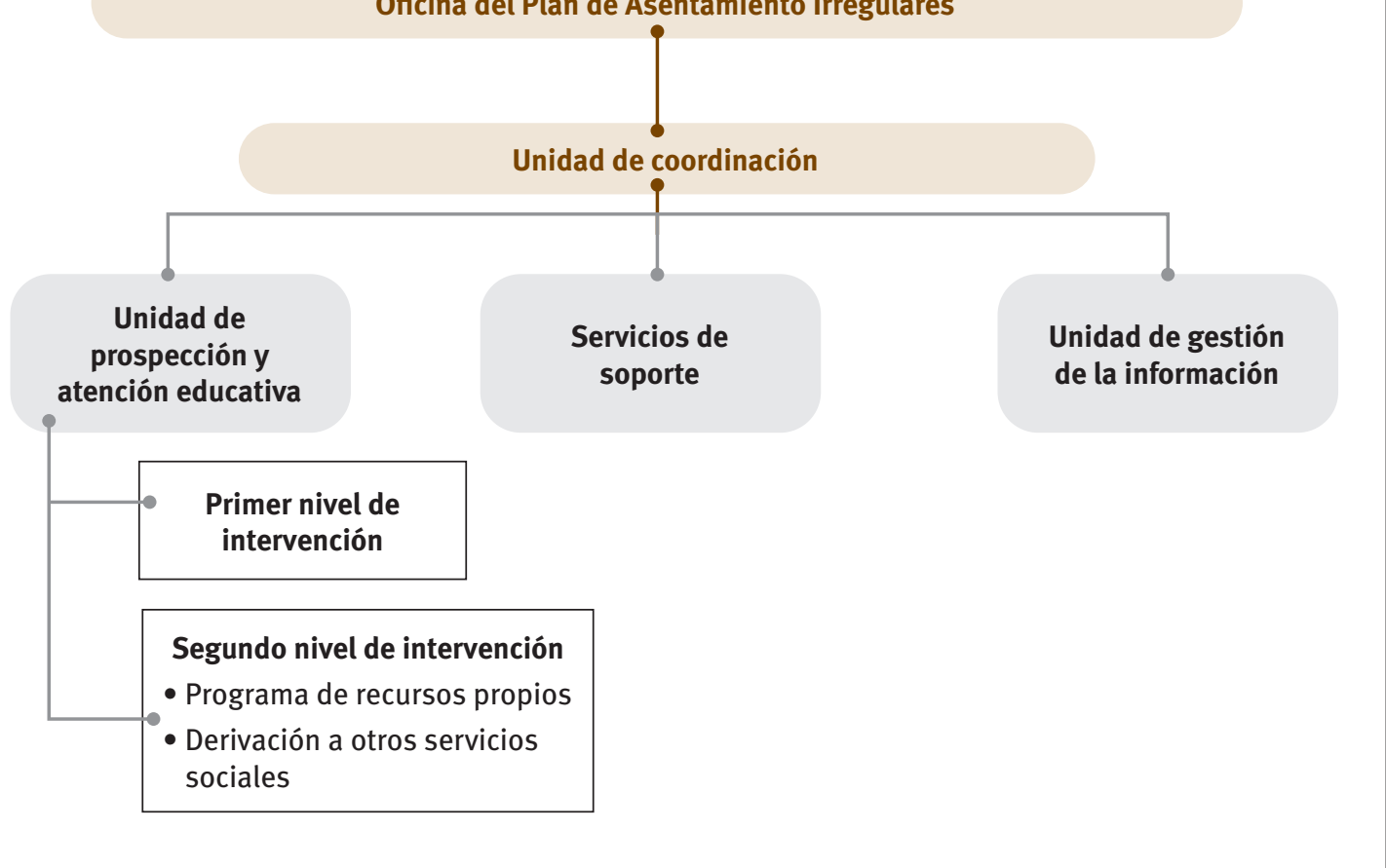

Fuente: Pliego de prescripciones técnicas particulares, Ayuntamiento de Barcelona.

y de definir y hacer seguimiento del plan de trabajo socioeducativos de manera individual, desplegando los recursos y servicios necesarios para trabajar los objetivos fijados en el plan.

3. La unidad de gestión de información. Es la responsable de la gestión y mantenimiento de las bases de datos, las referentes a los asentamientos y sus dinámicas, y las referentes a las personas que integran los diferentes asentamientos. Se encarga, igualmente, de elaborar censos e informes por su contraste en los diferentes espacios de coordinación técnica.

Para complementar la actividad de la oficina se dota a esta de una serie de servicios de apoyo:

1. Servicio de interpretación: necesario cuando existe barrera idiomática que dificulta la intervención social y para la traducción de documentos.

2. Servicio de asesoramiento jurídico: encargado de aquellos trámites requeridos para regularizar la situación administrativa de las personas usuarias que no disponen de permisos de residencia y/o trabajo en España.

3. Servicio de recursos para la capacitación: conjunto de actividades formativas para aumentar la empleabilidad de las personas usuarias y posibilitar su incorporación al mercado de trabajo.

4. Servicio de desarrollo de proyectos sociales y/o acciones singulares vinculadas a la OPAI, no definidos previamente en las funciones de las diferentes unidades del servicio.

\subsubsection{Niveles de intervención del servicio}

Se concretan dos niveles de intervención desarrollados por la unidad de prospección y atención socioeducativa, con la activación de los diferentes servicios de apoyo. Ambos niveles se entienden como un continuo en la estrategia global de atención socioeducativa.

\section{Primer nivel de intervención}

El objetivo es conocer cuáles son las características y realidades de los asentamientos y las necesidades, expectativas y demandas de las personas que los integran. Este primer nivel implica un conocimiento de las estructuras físicas de los asentamientos, su dibujo, las condiciones de seguridad y los riesgos que estos representan para las personas que viven allí. Igualmente, se evalúa el impacto que estos y las dinámicas asociadas tienen sobre el entorno territorial donde se ubican.

\section{Segundo nivel de intervención}

En el segundo nivel, y gracias a lo que se ha desarrollado en el primero, se diseña una intervención socioeducativa individual con cada 
persona usuaria, desplegando los recursos de apoyo del OPAI necesarios y todos aquellos servicios necesarios para cubrir las necesidades vitales y otros que se valoren desde el plan de trabajo. El objetivo es vincular el máximo número de personas en planes de trabajo que permitan adquirir a la persona una autonomía económica y personal para integrarse plenamente en la comunidad.

\subsubsection{Actividades del servicio}

Pueden integrarse en tres grandes bloques las actividades que llevó a cabo la Oficina del Plan de Asentamientos Irregulares:

1. Observatorio. La prospección planificada de los asentamientos, la observación de las dinámicas para identificar flujos, cambios y tendencias en su composición, la evaluación del impacto en el entorno y la recopilación y sistematización de los datos para construir nuevas líneas de acción, son las misiones principales de las que se ocupa la oficina en su vertiente de observatorio. El observatorio se nutre de los datos que proporcionan la Oficina del Plan de Asentamientos Irregulares (OPAI), el Servicio de Inserción Social en el Medio Abierto (SISMO) y el Servicio de Inserción Social de Familias Rom (SISFA ROM).

2. Intervención social. La intervención social se centra en la adherencia de las personas a planes de trabajo socioeducativos. No obstante, también se incide sobre el entorno en que viven y se relacionan, se identifican las dinámicas sociales y las características físicas de este entorno que puedan significar un riesgo para las personas que conviven: salubridad, estructura, etc.

3. Intervención comunitaria. La intervención comunitaria se sustenta en la evaluación del impacto que los asentamientos tienen sobre el entorno comunitario de recoger la percepción del tejido social del territorio donde se inscribe el asentamiento. Todo ello con el fin de poner en marcha líneas de trabajo, en colaboración con una red de actores del territorio, para facilitar la convivencia y la cohesión social.

Aparte de las actividades principales, los servicios de apoyo trabajan de manera complementaria con la unidad de atención social, con el apoyo de traductores e intérpretes en su caso, por:

a. el empoderamiento, adquisición de capacidades y habilidades personales para facilitar la inserción social y laboral;

b. el asesoramiento jurídico para evaluar las posibilidades de regularización administrativa y la obtención de los permisos de residencia y trabajo en el caso de personas extranjeras extracomunitarias en situación administrativa irregular; y c. el desarrollo de acciones y proyectos singulares que ayuden a la comprensión del fenómeno y avanzar en la mejora de la metodología de la intervención en sus dos dimensiones: individual y comunitaria.

En enero de 2021, el equipo pasa a denominarse Servicio de Atención Social al sinhogarismo en el Espacio Público (SASSEP) y los miembros de la antigua OPAl integran al nuevo equipo con las mismas funciones que tenían los integrantes del SISMO, pero añadiendo ahora los asentamientos a la observación y atención de las personas que pernoctan en el espacio público. El Servicio de Inserción social de Familias Rom (SISFA ROM) ahora es denominado Servicio de Inserción Social de Familias con Menores a Cargo (SISFAM).

El nuevo servicio distribuye el conjunto de su personal y sus recursos personales entre los diferentes territorios de la ciudad (diez distritos) creando equipos de seis profesionales que intervienen sobre el conjunto del fenómeno, sea cual sea su patrón de estancia y pernocta, integrando los asentamientos en las dinámicas de atención individual y colectiva. Además, se dota al servicio de una oficina técnica, a modo de observatorio, encargada del análisis de los datos que genera la actividad de los diferentes equipos territoriales y de la emisión de informes territoriales y generales sobre la evolución e impacto del sinhogarismo.

\section{Objetivo y metodología}

El objetivo de esta investigación es analizar la intervención profesional realizada en los asentamientos de la ciudad de Barcelona. A través de este objetivo principal se pretenden conocer los principales retos que se plantean a las políticas públicas en la gestión del espacio público. Para dar respuesta a estos objetivos hemos optado por una perspectiva cualitativa, de carácter exploratorio y descriptivo, que quiere facilitar la comprensión del fenómeno estudiado.

La técnica utilizada para la recogida de la información fueron las entrevistas en profundidad. Hemos trabajado con fuentes primarias, ya que se ha obtenido la información a partir de las entrevistas realizadas a los profesionales participantes.

\subsection{Muestra}

El método de muestreo utilizado es no probabilístico e intencional, ya que los profesionales entrevistados han sido seleccionados por los investigadores y posteriormente invitados a participar por los directores del área vinculada al Ayuntamiento de Barcelona. La muestra está constituida por seis técnicos del OPAI que realizan funciones diversas: directora del servicio, profesionales de los equipos de prospección y atención y la abogada. 
También se ha entrevistado a la directora de SISFAM y la directora del SIS (por su trayectoria en los asentamientos en la ciudad). En total se han realizado ocho entrevistas.

\subsection{Técnicas de recogida de información}

El instrumento de recogida de información ha sido la entrevista semiestructurada. A través de esta técnica o estrategia de conversación, el investigador puede adentrarse en el universo subjetivo de las experiencias desde el punto de vista de los otros (Taylor y Bogdan, 1996). Se ha diseñado un guion que ha estructurado la entrevista en cuatro ejes fundamentales: el servicio de atención, las personas atendidas, el trabajo realizado por los profesionales y los principales retos de las políticas públicas en el espacio público. Las entrevistas a los profesionales fueron realizadas en los espacios cedidos por las entidades y su duración fue de una hora.

\subsection{El trabajo de campo}

Los primeros encuentros con el equipo de investigación se inician en el mes de noviembre de 2018. Durante el año 2019, se realizaron reuniones con los responsables y directores de los servicios participantes para dar cuenta del proyecto, de sus objetivos y obtener su col colaboración para programar las entrevistas a los profesionales.

Durante el mes de abril, se iniciaron las entrevistas con el SIS y posteriormente al OPAI y el SISFAM. El trabajo de campo se finalizó en el mes de julio de 2019.

\subsection{Análisis de la información y consideraciones éticas}

El análisis de los contenidos se ha realizado sobre la base de tres categorías:

1. El servicio de atención.

2. El trabajo de los profesionales.

3. Las políticas desarrolladas en el espacio público.

Las categorías planteadas en la dimensión del servicio abordan aspectos relativos a su finalidad, organización y recursos. Las planteadas a los profesionales sociales introducen elementos de la relación de acompañamiento e instrumentos eficaces que lo facilitan. Y, finalmente, en la dimensión de las políticas sociales se plantean los principales retos para abordar el fenómeno de los asentamientos en la ciudad de Barcelona.

La presentación de los resultados sobre la base de estas categorías sigue la propuesta de análisis a partir de los relatos de los profesionales participantes en el trabajo de campo.
El estudio ha tenido en cuenta las consideraciones éticas señaladas en la Declaración de Helsinki de la Asociación Mundial Médica de 2013, posteriormente ampliada en la Declaración de Taipei de 2016. Por ello, se cuenta con el consentimiento informado de cada una de las personas participantes las cuales han prestado su testimonio con total conocimiento de causa y voluntad. Para preservar la confidencialidad de los datos, se han codificados las entrevistas con la siguiente pauta de numeración: E1, E2, E3, E4, E5, E6, E7 y E8.

\section{Análisis y discusión}

\subsection{El servicio de atención}

La definición de los asentamientos ha ido cambiando en relación con las transformaciones sociales y económicas vigentes en nuestras sociedades. En la actualidad, estos espacios informales son verdaderos observatorios de las desigualdades sociales (Delgado y Malet, 2007).

Un asentamiento es cualquier establecimiento humano que se dé en un espacio que no esté diseñado para ser una vivienda que no reúna las condiciones ni de habitabilidad ni accesibilidad y que tenga una permanencia en el espacio y con unas dinámicas particulares. Para mí los asentamientos siempre están vinculados con la vulnerabilidad social. (E6)

Es como un pueblo, como un pequeño pueblo. En general muchos asentamientos no se conocen entre ellos. Formalmente pueden ser barracas, naves industriales y bancos o locales. La mayoría son familias (se encargan de ellas el servicio de ASISPA). Estas familias tienen el espacio del asentamiento como el lugar de trabajo y de convivencia. (E2)

Es un espacio en vía pública o privada, en un solar o asentamiento, donde más de una persona se establece para hacer vida en común, comer, lavarse... y hacen pernocta en habitáculos de autoconstrucción o caravanas y camiones, todos ellos precarios. (E8)

Para atender a la diversidad de perfiles de las personas que conformaban los asentamientos de la ciudad, se creó el año 2013 un servicio específico. Los participantes en la investigación destacan que una de las principales funciones de este servicio es la localización y el conocimiento de los asentamientos a través de la tarea de prospección.

Conocer la realidad de toda la ciudad con esta información es generar conocimiento. Conocer cuál es la comunidad, qué demandas hacen, qué necesidades, qué intereses, cuál es su ciclo vital [...]. La dimensión comunitaria debe ser un elemento transversal y un pilar de la intervención; si trabajamos solo con los núcleos aislados y 
no trabajamos con toda la sociedad, creo que tenemos una mirada reduccionista y que no se podrá abordar el fenómeno en su dimensión [...]. La gente nos llega de diferentes vías, cuando nosotros hacemos prospección [...] que otro servicio te derive la persona [...] o las personas de forma espontánea se presentan aquí al servicio. El procedimiento es diferente según sea la vía de entrada. (E6)

Cada mes se elabora un informe sobre todos los espacios considerados asentamientos y espacios con dinámicas de asentamientos; aquí entran muchos locales, sobre todo de entidades bancarias. (E5)

La definición de prospección, según el Diccionario Práctico de Trabajo social, es "la exploración de posibilidades futuras basada en indicios presentes. Análisis de las alternativas a las que poder enfrentarse en un futuro próxima si se mantienen las condiciones del momento actual” (Arredondo, 2010: 139). El objetivo de esta función es profundizar en el conocimiento de estos espacios para planificar y mejorar la atención de las políticas públicas dirigidas a estas poblaciones.

Los profesionales entrevistados remarcan como otras funciones importantes del servicio la tarea de información y asesoramiento a las personas y familias.

Trabajamos con población que vive en asentamientos irregulares (solares, naves industriales de entidades bancarias) con el objetivo de mejorar la situación social de la persona. (E2)

Trabajamos en tres ejes: primero los derechos, tarjeta sanitaria y empadronamiento. Después trabajamos el tema de las formaciones y de la regularización [...]. El objetivo es que terminen abandonando la situación de vivienda que tienen. No es una forma digna de vivienda. $\left(E_{5}\right)$

Una de las funciones importantes que hacemos es el acompañamiento jurídico y la regularización la situación de las personas. (E4)

Estas funciones forman parte del acompañamiento socioeducativo, proactivo y de proximidad que tiene por objetivo conseguir la mejora de las personas a través de un proceso compartido y transformador de su situación (Alonso y Funes, 2009; Roche, 2007). Los profesionales destacan como principales puntos fuertes del servicio la regularización de los inmigrantes y la formación orientada a la inserción laboral.

Un punto muy favorable que tenemos desde el OPAl es que podemos regularizar a las personas que no tienen papeles. Muy pocos servicios y especialmente los que trabajan en calle no pueden conseguir esto [...]. Nosotros somos de los pocos servicios que regularizamos a personas, aunque sea pocas personas lo podemos hacer [...]. El servicio de la abogada es fundamental para poder realizar esta actividad. [...] ¡Estas son las personas que te hacen sentir bien! (E2)

Como fortaleza sí que la parte jurídica es muy importante. La oferta de prácticas no remuneradas en empresas facilitaban la regularización de muchas personas, pero ahora eso no lo tenemos garantizado (desde hace un par de meses). Ya no es igual que antes. Al perder esta parte ya no es lo mismo, era un aspecto diferencial que como servicio podían ofrecer. Nosotros no tenemos recursos, la mayoría los piden fuera. (E3)

La regularización de los inmigrantes permite orientar la intervención hacia una verdadera ciudadanía inclusiva, consiguiendo una participación activa de las personas atendidas (Matulič, 2015). Las situaciones extremas en las que se encuentran las personas hacen necesario un trabajo intensivo con los diversos servicios de los sistemas de bienestar social.

Entre las principales limitaciones del servicio se destacan la falta de recursos propios y la necesidad de articular un verdadero trabajo en red con los servicios y agentes implicados.

Uno de los hándicaps es la población heterogénea que tenemos y la situación de vida muy extrema en la que se encuentran. Hay muchos ámbitos que se relacionan, problemas de salud, dificultad de documentación [...]. Con personas en estas situaciones las expectativas son muy bajas. (E2)

Tienen muchas necesidades que no podemos cubrir, esto hace que, con las vidas tan complicadas que llevan, los planes de trabajo que podrían ser en un año sean en tres. (E4)

El trabajo en red aportaría dar un servicio con mayor calidad y más eficiente. (E6)

Ante la complejidad de las situaciones de pobreza extrema que presentan las personas que viven en los asentamientos se hace necesaria una respuesta integral. Esta orientación la encuentran en varios documentos nacionales y europeos que indican la necesaria colaboración y coordinación general con varios departamentos para favorecer una atención global y especializada (Comisión Europea, 2013; Federación de Entidades de Apoyo a Personas sin Hogar, 2013).

Los profesionales expresan como principales retos del servicio disponer de más recursos propios para asegurar una mayor autonomía en el acompañamiento e implementar un trabajo integral y en red que favorezca los procesos de capacitación profesional y regularización administrativa de las personas atendidas. 
Creo que nos deberíamos centrar más en la capacitación profesional. Porque si hacemos esta tarea podemos dar salida a la situación de sinhogarismo. Otro tema sería ganar autonomía. Debemos hacer muchos contactos y derivación a otros servicios. (Е3)

Tenemos dificultades para afrontar los casos de manera integral porque no tenemos recursos; esto nos limita mucho, siempre tenemos que trabajar con algún otro servicio que nos tramite las ayudas [...]. También otra dificultad es el elemento cultural, no tenemos una visión intercultural. Si no hay un entendimiento no habrá una vinculación. Siempre somos nosotros interpretando lo que pensamos que quieren. (E6)

Creo que tenemos que encontrar nuevas formas de trabajar, pero no a nivel policial, sino educativo y social. Por ejemplo, nos ayudaría mucho tener más conocimiento de la población con la que trabajan, como hemos hecho en el caso de las familias rumanas. Quizá nos hace falta más formación, de cómo trabajar y cómo colaborar entre los servicios. (E1)

\subsection{El trabajo de los profesionales}

Los relatos de los profesionales nos indican que el primer nivel de intervención en los asentamientos se inicia con la detección. Según Maya (2008), a través de esta acción se realiza una primera aproximación al conocimiento de la realidad. El objetivo de la acción durante esta fase se observar y analizar las características y realidades de los asentamientos, así como las necesidades, expectativas y demandas de las personas que los integran.

Se nutre principalmente de dos vías: la primera es la observación directa por parte del equipo. Tenemos seis educadoras/es y tenemos la ciudad dividida. Nos presentamos como servicio del ayuntamiento con el objetivo de mejorar la situación de las personas. (E2)

El primer contacto siempre lo hacemos en el asentamiento. Después hacemos una entrevista en el servicio, donde hacemos una exploración y tenemos una batería de recursos que utilizamos según las necesidades [...]. Si hay que coordinarse o vincularlo a otros servicios nos coordinamos a estos servicios. (E3)

Primero se hace una observación no participante, [...] para prepararnos la intervención. Nos da mucha información. La primera entrevista la hacemos en el despacho, pensamos que garantizar un espacio o un contexto más favorable, más íntimo, más seguro, nos pueden explicar más su trayectoria. Siempre teniendo en cuenta que el protagonista es la persona [...]. Trabajamos desde motivarlas hasta vincularse al servicio. (E6)
Tal como podemos identificar en los relatos de los profesionales, a partir de esta primera acción se inicia un trabajo de proximidad que reconoce las posibilidades educativas en el medio natural. La proximidad se entiende como una forma de actuación proactiva y construida conjuntamente "con" y lo más "cerca posible" de la persona (Roche, 2007). Durante esta primera fase se utilizan técnicas como la observación y la entrevista, que acompañan la exploración de los problemas y demandas de las personas atendidas.

Las demandas presentadas son diversas y están vinculadas a sus expectativas, a los procesos de exclusión social y a las características culturales de las personas. En relación con los perfiles, los participantes en la investigación destacan que la mayoría son familias rumanas de los países del Este y personas solas procedentes de países no comunitarios.

Nosotros lo que hacemos es que lo contamos todo de forma muy clara desde el principio. Sobre todo los que no son comunitarios. Con estos hacemos un "baño de realidad", pero les damos las opciones. Recogemos mucho sus expectativas, pero situamos cuál es la realidad aquí. Entre los que son comunitarios, nos encontramos perfiles nómadas, por ejemplo gitanos-rumanos. Este grupo configura casi un $80 \%$ de las personas atendidas. En este caso, hablamos de un estilo de vida. Cada dos meses se van a sus países de origen. (E3)

Va mucho por perfil. Tenemos perfiles muy variados. Una tercera parte son gitanos rumanos y básicamente el trabajo que se hace con ellos es renovación de DNI, tarjeta sanitaria... Después tenemos el perfil de los africanos (senegaleses, etc.), que les interesan las ayudas para personas sin hogar, pero también piden poder trabajar. $Y$ un $3 \%$ son personas con problemas de drogadicción, salud mental... Y ahí tú tienes que ser más directivo. La necesidad no la verbaliza el usuario, tú la has de ir dirigiendo. (E2)

Con los subsaharianos es totalmente diferente, se han jugado la vida para llegar aquí. Vienen a integrarse, a coger el trabajo que haga falta. El acompañamiento es diferente. Es un colectivo para recibir asertivamente un acompañamiento. (E5)

Hay una casuística muy grande. Tenemos limitaciones con las personas inmigrantes; la barrera es la ley de extranjería, en estos casos llevamos años con ellos... También una de cada tres personas que se encuentran en los asentamientos son gitanos-rumanos. Para ellos su modus vivendi es marchar a su país, volver... (E2)

Depende de la familia; en algunas su proyecto migratorio es para ganar dinero y poder volver a su país unos años más tarde y construirse una casa. Otros, en cambio, se plantean quedarse a vivir aquí y hacer un cambio de su modus vivendi. (E8) 
El abordaje de cada uno de estos colectivos requiere de varios tipos de acompañamiento. Por ejemplo, la presencia de menores en los núcleos familiares de itinerantes y rumanos, 0 la situación de irregularidad administrativa de la mayor parte de los subsaharianos implican diseñar trayectorias diferenciadas en función de sus circunstancias (López y Sáez, 2009).

Los tipos de demandas que realizan las personas se orientan a la vivienda y la inserción laboral y, en el caso de los inmigrantes, al proceso de regularización administrativa. Según De Robertis (2003) la demanda es una acción realizada por la persona con el fin de encontrar soluciones a sus dificultades. A través de esta acción se movilizan deseos y expectativas que tienen la finalidad de reducir la frustración y sufrimiento que entraña. Según Teresa Rossell (1987), para involucrar a la persona en el proceso de estudio y de ayuda hay que empezar por tratar lo que más le preocupa, lo que más le interesa y satisfacer los aspectos que considera más prioritarios, lo cual constituirá un paso, un medio, para conseguir finalidades más amplias.

Los profesionales relatan que también llegan demandas de otras personas y servicios. En estos casos hablamos de demandas indirectas.

El aviso de asentamientos puede venir de diversas vías, como por ejemplo de un vecino que puede poner un IRIS, que es como una instancia que nos avisa que allí existe un grupo de personas que nosotros no hemos detectado. 0 de la policía que los detecta, o de un equipo educativo, por ejemplo, el SIS que lo detecta... (E2)

En estos tipos de demandas es muy importante incorporar a los servicios y agentes implicados para trabajar de manera adecuada la derivación y posterior implicación de los profesionales en el acompañamiento (Maldonado, 2008).

En el segundo nivel de intervención se desarrolla la acción socioeducativa con las personas atendidas, desplegando los recursos de apoyo del OPAl y todos aquellos servicios necesarios para cubrir las necesidades vitales, así como otros que se valoren desde el plan de trabajo. El objetivo es vincular el máximo número de personas en planes de trabajo que les permitan adquirir una autonomía económica y personal para integrarse plenamente en la comunidad.

Los relatos de los profesionales destacan como bases fundamentales de la relación profesional la vinculación y el trabajo de acompañamiento centrado en la persona.

Saber escuchar, tienen mucha necesidad de hablar. [...] Viven en situación de mucha angustia, creada por una indiferencia y esta indiferencia genera violencia. [...] Por eso, es muy importante la contención emocional que pasa por el reconocimiento del sentimiento. $\left(E_{5}\right)$
Para trabajar el vínculo, lo que aplicamos mucho nosotros es la transparencia en la información. Esto evita situaciones de malentendidos y al otro le da confianza en la relación. Lo que es más complicado para trabajar el vínculo son las barreras institucionales. Por ejemplo, cuando tenemos un desalojo de un asentamiento. 0 situaciones que nos hacen recoger datos que no benefician a las personas. También entre las dificultades estarían las situaciones donde trabajamos con barreras de la ley de extranjería. (Е3)

Hacerles saber que se les escuchará y les ayudará en la medida de lo posible. Son familias que vienen con una mochila de rechazo, que han sufrido rechazo en toda su trayectoria migratoria y a menudo en su llegada a la ciudad; por tanto, una buena acogida es clave para que se sientan respetadas y valoren el cumplimiento del plan de trabajo. (E8)

Construir la relación en clave de acompañamiento social supone generar una vinculación centrada en la comprensión y en la confianza. Estamos ante personas que han tenido varias pérdidas y que se encuentran en una situación de fuerte impacto emocional (Matulič, 2015). El reconocimiento del otro genera el vínculo necesario que hará posible la transformación hacia el cambio (Howe, 1997).

Las personas son siempre el sujeto. Ellos nos dicen: “¿Tú me puedes ayudar?”, y yo les digo: “No, yo no te voy a ayudar, tú decides qué vas a hacer con tu vida. Tú eres el actor: sujeto y objeto. (E2)

El marco teórico que tiene todo el equipo, todo el mundo tiene claro que el protagonista que debe cumplir un plan de trabajo es el usuario, que es él quien tiene que dirigir su vida; el asistencialismo y el paternalismo lo dejamos siempre fuera. (E6)

Uno de nuestros objetivos es acompañar para empoderar al usuario para que a posteriori pueda hacer las gestiones de manera autónoma. (E8)

Poner a la persona en el centro del acompañamiento implica fomentar su autonomía. A través del plan de trabajo compartido se logra la participación activa de las personas en sus procesos y se construye una ciudadanía inclusiva basada en el reconocimiento de los derechos. Como nos recuerda Adela Cortina (1997), todo proceso de acompañamiento social debe tener como uno de sus objetivos principales la promoción del ejercicio de una plena ciudadanía social.

El acompañamiento incluye también el trabajo con la comunidad, que se orienta a la sensibilización e información a los vecinos y vecinas de los barrios donde se encuentran los asentamientos. 
Todas estas ocupaciones están generando un impacto en la comunidad, los vecinos y las vecinas se posicionan. Tenemos que trabajar esto. [...] Intentamos identificar líderes comunitarios y equipamientos que estén próximos, establecemos una relación para ver si serán aliados o no. (E6)

Por la parte comunitaria no dedican mucho tiempo. Siempre hemos tenido dificultades a nivel político. Este tema es sensible y no gusta que lo impulsamos mucho. Sí que trabajamos en esta parte cuando hay problemas de convivencia. Nuestro trabajo es reactivo, no la organizamos. Hacemos una importante labor de sensibilización e información. (Ез)

Tal y como nos indican las entrevistas, uno de los objetivos del trabajo con la comunidad es abordar las situaciones de conflicto para evitar problemas de convivencia (Morata, 2009). A través de la tarea de prospección, los profesionales evalúan el impacto que puede tener el asentamiento en el entorno comunitario, generando vínculos con el tejido social para facilitar la convivencia y la cohesión social. Este trabajo favorece los procesos de inclusión social de las personas acompañadas y genera sinergias entre todos los actores implicados (Subirats, 2010).

Se hace contención con la comunidad vecinal, se recoge los malestares y se da respuesta a los IRIS de la ciudadanía. El malestar de la comunidad se transmite a las familias para que puedan mejorar y rectificar actos incívicos y puedan así favorecer la convivencia con el resto del vecindario que vive cerca. Generalmente lo reciben bien, porque las familias saben que les conviene tener buena relación con el resto de la comunidad. (E8)

La complejidad de las situaciones que presentan las personas hace necesario un trabajo conjunto entre servicios y agentes implicados. Las entrevistas destacan la importancia de la vinculación con servicios de información y asesoramiento jurídico, de salud o de servicios sociales.

Trabajamos mucho con los CAPS, oficinas de atención al ciudadano, con la abogada del servicio, consulados, con el SOC, con albergues, comedores sociales, Cáritas [...]. (E2)

Mis coordinaciones son con los juzgados, la Policía Nacional y los Mossos. Gestión de acompañamiento jurídico a los juicios, no hacemos representación. (E4)

Varios autores destacan la importancia de establecer canales de comunicación y sistemas de coordinación eficaces para atender de forma más efectiva las situaciones complejas que presentan las personas en procesos de exclusión social (Martínez; MiraPerceval; Redero, 1996).

Entre las limitaciones más importantes, se destacan las barreras legales que dificultan el acompañamiento de las personas inmigradas, las dificultades de coordinación entre los servicios implicados y la carga de trabajo de los profesionales.

La situación de la sociedad actual y de las leyes, el tema de regularización de papeles que tú quieres garantizar [...] frustra mucho e imposibilita procesos de éxito. (E5)

Hay tres servicios que son complementarios; serían el SIS, el SISFA ROM y el OPAI. Necesitamos estar en continua comunicación. (E5)

En los espacios de los asentamientos en el espacio público comenzaron a hacer un trabajo conjunto (SIS/asentamientos), un protocolo del OPAl y nosotros. Fue complicado encontrar el encaje y qué función tenía que hacer cada uno y qué hacer [...]. Veremos cómo iremos encajando el trabajo nuestro con el OPAI. [...] Los asentamientos en el espacio público también deben regular y ver cómo lo trabajamos. (E1)

Tener protocolos en la relación con los otros servicios nos ayudaría mucho. Sería lo que nos facilitaría más nuestra labor. También el hecho de que nosotros somos un servicio nuevo, este instrumento nos ayudaría a ahorrarnos la tarea de explicación de lo que somos y qué hacemos. (E3)

Mucho trabajo para los profesionales que somos. No damos abasto. La parte positiva es que somos un equipo muy cohesionado y estamos muy motivados. No llegamos a todos. (E2)

Finalmente, los participantes destacan como principales retos en la atención social incrementar la formación de los profesionales para atender de una manera más holística e integral, incorporar la visión intercultural en la atención y sistematizar la práctica profesional.

Creo que tenemos que encontrar nuevas formas de trabajar, pero no a nivel policial, sino educativo y social. Por ejemplo, nos ayudaría mucho tener más conocimiento de la población con la que trabajan, como hemos hecho en el caso de las familias rumanas. Quizá nos hace falta más formación de cómo trabajar y cómo colaborar entre los servicios. $\left(E_{5}\right)$

Tenemos dificultades para afrontar los casos de manera integral porque no tenemos recursos, esto limita mucho, siempre tenemos que trabajar con algún otro servicio que nos tramite las ayudas [...]. También otra dificultad es el elemento cultural; no tenemos una visión intercultural. Si no hay un entendimiento no habrá una vinculación. Siempre somos nosotros interpretando lo que pensamos que quieren. (E6)

Si se pudiera hacer un proyecto donde se pudieran hacer planes de trabajo muy individualizados y muy adecuados a cada persona, su formación, su trayectoria previa, y si 
se les pudiera asegurar un mínimo de estabilidad en la vivienda y en la manutención, posiblemente tendríamos otra posibilidad. (E4)

\subsection{Las políticas desarrolladas en el espacio público}

El desarrollo de los asentamientos en la ciudad ha generado la articulación de políticas públicas orientadas a la atención y control de las poblaciones excluidas. La percepción de peligrosidad vigente en el imaginario colectivo legitima la articulación de políticas de control sobre estas poblaciones (Cabrera, 2008; Ferreres y Fernández, 2014; Palleres, 2004).

Los participantes en la investigación afirman que estamos ante un fenómeno que continuará evolucionando y en el que se necesitan nuevas miradas y acciones. La complejidad de situaciones que presentan las personas que se encuentran en situación de exclusión social hace necesaria la articulación de políticas públicas que puedan acompañar estos procesos desde una perspectiva transversal y estratégica, que incluya nuevos enfoques centrados en las causas y en la corresponsabilidad entre Administraciones, agentes sociales y tejido social (Subirats; Afama; Obrador, 2009).

La parte logística es incuestionable. Barcelona va creciendo y cada vez habrá menos solares abandonados. No creo que esta realidad desaparezca, sí que seguramente evolucionará [...]. El perfil yo creo que se irá manteniendo, seguirá habiendo gitanos-rumanos, y marroquíes porque están cerca y siempre han estado muy presentes en Barcelona [...] y creo que africanos ha bajado. (E2)

Es difícil de prever, pero nadie ha venido a analizar, como hacéis vosotros, cuáles son las raíces de la situación. Todo lo que sale son ofertas o recursos para atender las necesidades que vamos teniendo. Pero si nadie analiza cuáles son las causas... (E3)

El abordaje debería ser más holístico, tanto a nivel de servicios como de recursos y profesionales. Una estrategia de ciudad. (E6)

Las limitaciones legislativas en materia de inmigración y la falta de políticas de vivienda dificultan el trabajo de atención a las personas más vulnerables desde los servicios sociales (Trilla y Vilanova, 2017).

La situación de la sociedad actual y de las leyes, el tema de regularización de papeles que tú quieres garantizar [...] frustra mucho e imposibilita procesos de éxito. $\left(E_{5}\right)$

Vivienda no solo para este servicio, debería ser algo más general. Es el principal problema. (E4)
Para mí sería muy importante la creación de una estructura más integral. También es importante no ver a la persona que está en un asentamiento y darle de comer, sino ver qué posibilidades o herramientas podemos dar a las personas para que ellas mismas lo consiguen. Por ejemplo, el modelo Housing First es un buen ejemplo de lo que estamos hablando. (E3)

Los profesionales afirman que la complejidad de las situaciones que se atienden necesita de nuevas metodologías de intervención en la calle. Desde esta perspectiva, se debería profundizar en los diversos perfiles desde un enfoque intercultural y comunitario que incorpore un trabajo en red entre todos los servicios implicados.

Tenemos perfiles cada vez más complicados, es un riesgo pero también es un reto. (E6)

Hay que enmarcar en un marco teórico; las cosas que hacemos las tenemos que poder justificar desde una metodología, desde un objetivo claro. Debemos reflexionar, planificar, debemos evaluar para poder rediseñar. (E6)

Si se cambia la intervención y se hace un trabajo coordinado podemos ir avanzando; si no, podrá ser un polvorín. (E1)

Intentaría mejor la coordinación a nivel de intervención de calle. ( $\left.E_{5}\right)$

Hay que incluir la perspectiva comunitaria y la intercultural. (E6)

\section{Conclusiones}

Los cambios sociales y económicos presentes en nuestras sociedades están impactando de forma directa en las personas más vulnerables. La presencia de asentamientos en la ciudad de Barcelona es una muestra de cómo las desigualdades pueden incidir de manera punzante en determinados grupos sociales, generando situaciones de precariedad extremas.

La Administración Pública, como encargada de la regulación y control del espacio público, ha articulado diversas formas de atención en los últimos años. En 2013, desde el Ayuntamiento de Barcelona se planteó la creación de un plan para atender las diversas situaciones que presentaban los asentamientos de la ciudad (grupos itinerantes, personas procedentes de etnias y países extracomunitarios, entre otros), esta propuesta significó un paso importante en el diseño de un modelo integral hacia los grupos más vulnerables de la ciudad. A través de este plan se consensuó la definición de asentamientos y se planteó la creación de una oficina especializada (OPAl) para atender estas situaciones de extrema vulnerabilidad. La configuración de estos espacios de convivencia 
(formales e informales) ha ido cambiando a lo largo del tiempo, representando un verdadero observatorio de las desigualdades sociales en la ciudad.

Siguiendo la tipología ETHOS, las personas objeto de atención del OPAI se encuentran en una situación de exclusión residencial en las categorías vinculadas a sin techo y viviendas inadecuadas.

Los resultados de la investigación nos indican que en estos últimos años se ha constatado que hay una serie de colectivos a los que los recursos actuales de la red de atención a las personas sin hogar dan una respuesta parcial. Es lo que podríamos llamar "no insertables", personas que por causas diversas no alcanzarán un grado de autonomía personal y económica y que, carentes de apoyos familiares, requerirán de una asistencia continuada. Al igual que en otros servicios y equipamientos de la red municipal de atención a personas sin techo, los técnicos del OPAI constatan esta realidad e identifican dos subgrupos de personas con serias dificultades a la hora del abordaje integral de su situación:

1. Personas refractarias a la atención social, con larga trayectoria de vida en la calle, con dificultades de adaptación y problemas asociados no resueltos que les impiden adaptarse a los diferentes equipamientos de atención social de los que dispone la red. Rechazan cualquier intervención porque no están dispuestos a adquirir los compromisos implícitos en el plan de trabajo, mientras que los que en un principio se muestran permeables a los acuerdos son incapaces de cumplirlos, autoexcluyéndose de esta manera de la atención que se les ofrece. Su relación con los servicios se caracteriza por la falta de adherencia y de continuidad, los abandonos constantes por incumplimientos reiterados de la normativa mínima de convivencia y la incapacidad para seguir los acuerdos y las acciones pactadas en los planes de trabajo, con reingresos regulares en cortos períodos de tiempo.

2. Personas sin otras alternativas que, a pesar de ser susceptibles de atención por parte de otros sistemas de protección, no pueden acceder por falta de capacidad o por no reunir todas las características que hacen posible el acceso. También enfermos convalecientes que no tienen alternativas de alojamiento en tanto dure el proceso de convalecencia, o enfermos crónicos sin apoyo que requieren de atención sociosanitaria continuada. En resumen, un conjunto de personas que, una vez finalizadas todas las acciones posibles, no se encuentran en situación de vivir sin apoyo social, bien por razones de edad, de incapacidad personal $\mathrm{y} / 0$ física, etc.

Uno de los colectivos más problemáticos para garantizar una atención continuada con garantías de éxito e integración es el colectivo de extranjeros no comunitarios que, sin permisos de residencia, quedan excluidos del mercado de trabajo y sin posibilidades de percibir subsidios sociales. En estos casos, el retorno al lugar de origen es el principal objetivo. Pero este retorno es, en la mayor parte de casos, rechazado sistemáticamente. El escaso o nulo desarrollo de sistemas de protección social en sus países de origen, hace que prefieran continuar en nuestro país. Aunque sus condiciones de vida son precarias y se caracterizan por muchas y diversas carencias, son preferibles a las condiciones de sus países de origen. El problema con este colectivo es la situación administrativa al que está sometido. Si bien la ley de extranjería prevé la expulsión y retorno de los inmigrantes sin regularizar, esta medida se aplica en contadas ocasiones. Así, las personas sin permisos de residencia y trabajo no son devueltas a sus países de origen, pero tampoco pueden vivir en condiciones de igualdad en España. Aún peor, no se pueden garantizar la subsistencia ni la autonomía personal a través de un trabajo remunerado por su condición administrativa, a la que hay que añadir los problemas sociales y personales a los que los vierte su situación administrativa que se podría definir como a una situación límbica. Además, a menudo la persistencia de esta situación agrava problemas de salud y de salud mental.

El grado de desestructuración de estas personas y sus posibilidades de adquirir una plena autonomía económica y personal no permiten una intervención integral tal y como se realiza en los recursos existentes, orientada a la salida definitiva del sistema de protección. Se debe plantear la posibilidad de una intervención asistencial, dentro de unos marcos proactivos, constituyendo el servicio más básico de atención a las personas en un estadio consolidado, con imposibilidad manifiesta de acceder a otros recursos más normativizados.

Los participantes en la investigación afirman que, ante la complejidad de las situaciones que se atienden, se necesitan implementar nuevas metodologías de intervención en el espacio público. Desde esta perspectiva, se debería profundizar en los diversos perfiles desde un enfoque intercultural y comunitario que incorpore un trabajo en red entre todos los servicios implicados. Los profesionales cuentan con un soporte formativo, pero no con una supervisión profesional. Se deberían implementar estos apoyos a los técnicos de los equipos como un instrumento de calidad en la atención social. Finalmente, los profesionales señalan como principales dificultades las cargas de trabajo y la falta de recursos propios en el servicio. Esta situación genera un sentimiento de frustración ante los casos y una situación de dependencia con otros servicios del sistema de bienestar.

Como principales fortalezas del equipo profesional se destaca la alta especialización y la experiencia de sus técnicos. Entre las tareas más importantes desarrolladas por los profesionales destacan: la transmisión de conocimiento a otros servicios de espacio público y los servicios sociales; el trabajo 
comunitario y la pedagogía hacia la vecindad y actores de los diferentes territorios; la atención de proximidad y personalizada y el conocimiento de los itinerarios vitales de las personas usuarias. $Y$, entre las principales fortalezas del servicio, se destaca la atención jurídica propia y la articulación de procesos de capacitación, así como la posibilidad de prácticas no laborales en empresas del sector privado.

La intervención exitosa pasa por una solución residencial que, desgraciadamente, es difícil en el contexto actual. Las políticas de vivienda no dan respuesta a las usuarias del sistema de atención social al sinhogarismo y con rentas bajas: imposibilidad de acceder a viviendas de protección oficial (VPO) a través de la mesa de emergencias, inexistencia de ayudas al alquiler para personas sin vivienda, falta de pisos de emergencia social, etc. Igualmente, los servicios sociales de territorio no disponen de alternativas a los centros residenciales $u$ otros servicios de vivienda transitoria pensados para las personas $\sin$ hogar. Esto hace que, actualmente, las atenciones se prolonguen por falta de vivienda en establecimientos como pensiones, centros residenciales, viviendas de inclusión, etc., por falta de vivienda a precios asequibles.

La consecución de vivienda de alquiler como objetivo último de la intervención es un camino lleno de dificultades entre las que destacan, sobre todo, condicionantes externos bastante conocidos: las dinámicas de oferta/demanda de los mercados de trabajo y vivienda. Dicho de otro modo, las soluciones positivas, salidas con vivienda y autonomía económica, dependen no sólo del trabajo realizado por los referentes, correferentes y el resto de operadores, también de las posibilidades de las personas para encontrar un trabajo o aumentar ingresos y poder acceder a una vivienda de alquiler. Estas posibilidades no solo dependen de los esfuerzos personales que se destinen, sino también de las capacidades reales de competencia. La escasa formación y preparación hacen que algunas personas se vean abocadas a trabajos de escasa cualificación profesional y, por tanto, con sueldos que no superan los 500 euros mensuales, o si los superan, lo hacen muy ligeramente. Si a esto le añadimos los precios de los alquileres en Barcelona y las ciudades de su área de influencia $\left(14,1\right.$ euros $/ \mathrm{m}^{2}$ de media el tercer trimestre de 2020 en el municipio de Barcelona), encontramos que los ingresos pueden ser insuficientes para hacer frente al pago de un alquiler.

A estos déficits hay que añadir los problemas derivados de la conexión con el mercado de trabajo. En este campo se constata la falta de empleabilidad de determinadas personas. La falta de formación, trayectoria laboral, dificultades administrativas (falta de permisos de residencia) y, en ocasiones, motivación explícita, aboca a parte de las personas usuarias a convertirse en trabajadoras en precario de manera endémica, que transitando del desempleo a trabajos protegidos, con la limitación que estos suponen, ya trabajos no regularizadas contractualmente, que implican ingresos escasos e irregulares, lo que ayuda a consolidar situaciones de vulnerabilidad e impiden un acceso a la vivienda en condiciones óptimas para mantenerlo. Por otra parte, los problemas de falta de instrucción, el bajo dominio de la lengua en el caso de los migrantes, la falta de experiencia, una edad avanzada, la edad fértil en las mujeres, las situaciones de discapacidad parcial o enfermedades crónicas que imposibilitan realizar determinados trabajos (precisamente aquellas donde estas personas encuentran una mayor oferta), o cualquier combinación de éstos con otros elementos, terminan limitando el acceso al mercado de trabajo en unas mínimas condiciones de dignidad y estabilidad. Junto a estas situaciones objetivas, es importante remarcar la importancia de los factores relacionales. Así, las personas que han perdido referentes familiares, que no disponen de lazos sociales y vecinales y que, por tanto, viven aisladas en el núcleo familiar, o en soledad, tienen difícil su rehabilitación social, ya que no tienen en qué o en quien fundamentar su trayectoria de inclusión. En este sentido, añadiendo a este aislamiento la falta de recursos económicos y las escasas posibilidades de insertarse en el mercado de trabajo con garantías de estabilidad, el riesgo de dependencia institucional y de subsidiariedad es más que evidente. Hay que complementar los cuidados básicos y el apoyo profesional con la incidencia de las Administraciones sobre los mercados de trabajo y vivienda; de otro modo, la inclusión no puede ser satisfactoria en los casos más vulnerables.

Las propuestas de mejora en las políticas públicas se orientan a la articulación de políticas de vivienda que atiendan los diversos procesos de exclusión residencial que presentan las personas que conforman los asentamientos de la ciudad. También se hace necesario desarrollar políticas activas de formación y empleo dirigidas a los colectivos más vulnerables con mayores dificultades de inserción laboral. Ante la complejidad de situaciones que presentan las personas atendidas, los profesionales proponen mejoras en la articulación de políticas públicas que puedan acompañar estos procesos desde una perspectiva transversal y estratégica, que incluya nuevos enfoques centrados en las causas y en la corresponsabilidad entre todos los agentes implicados. La nueva reorganización del servicio tiene un hito importante y nuevos retos por delante que podrá ser valorada en los próximos años. 
ALONSO, I. y FUNES, J. (2009): “L'acompanyament social en els recursos socioeducatius", Revista Educació social: Revista d'intervenció socioeducativa, p. 27-45.

ARREDONDO, R. (2010): Diccionario Práctico de Trabajo social, Málaga, Colegio Oficial de Diplomados en Trabajo social de Málaga.

ASOCIACIÓN MÉDICA MUNDIAL (2013): Declaración de Helsinki de la AMM - Principios éticos para las investigaciones médicas en seres humanos, Helsinki, <https://www.wma.net/es/policiespost/declaracion-de-helsinki-dela-ammprincipios-eticos-para-las-investigacionesmedicas-enseres-humanos/>.

- (2016): Declaración de la AMM sobre las Consideraciones Éticas de las Bases de Datos de Salud y los Biobancos, Taipei, 〈https://www.wma.net/es/ policies-post/declaracion-de-la-ammsobre-lasconsideraciones-eticas-de-las-bases-de-datosde-saludy-losbiobancos/>.

AYUNTAMIENTO DE BARCELONA (2020): Servei d'Inserció Social de Famílies amb Menors (SISFAM), <https://ajuntament.barcelona.cat/ prevencio/ca/servei-inserci\% $\mathrm{C}_{3} \% \mathrm{~B} 3$-socialfam $\% C_{3} \%$ ADlies-rom-sisfarom .

BACHILLER, S. (2009): “Significados del espacio público y exclusión de las personas sin hogar como un proceso de movilidad forzada", REIS. Revista española de investigación sociológica, 128, p. 125-137.

BARRY, M. y MAYSON D. (2000): Característiques dels establiments irregulars en un cas de restitució de terra rural: Elandskloof. Sud-àfrica, 〈http:// www.socresonline.org.uk/5/2/barry.htmls.

BRENNER, N.; PECK, J. y THEODORE, N. (2009): “Urbanismo neoliberal: la ciudad y el imperio de los mercados”, Sociales, 66, Santiago de Chile.
BUTLLETÍ OFICIAL DE LA PROVINCIA DE BARCELONA (2006): "Ordenanza de medidas para fomentar y garantizar la convivencia ciudadana en el espacio público de Barcelona", Barcelona, BOP 20, Anexo 1, 24 de Enero.

CABRERA, P. (1998): Huéspedes del aire. Sociología de las personas sin hogar en Madrid, Madrid, Universidad Pontificia de Comillas.

- (2008): “Les persones sin hogar, hoy”, Revista del Ministerio de Trabajo e Inmigración, 75, p. 5174.

CARR, S.F.; FRANCIS, M.; RIVLIN, L. y STONE, A. (1992): Public space, Cambridge University Press.

COLOMER, R. y RUSTULLET, J. (2010): Diccionari de Serveis Socials, Barcelona, Generalitat de Catalunya, Departament de Benestar Social.

COMISIÓN EUROPEA (2013): Confronting Homelessness in the European Union Accompanying the document Communication from the Commission to the European Parliament, the Council, the European Economic and Social Committee and the Committee of the Regions, serie Staff Working Documents, Bruselas, Comisión Europea.

CORTINA, A. (1997): Ciudadanos del mundo: hacia una teoría de la ciudadanía. Madrid, Alianza.

DAVIS, I. y SAFE SHELTER (1987): “Within Unsafe Cities: Disaster Vulnerability and Rapid Urbanisation", Open House International, 12, 3, p. 5-15.

DE INÉS, A.; GUZMÁN, G.; VERDAGUER, M. y CONTRERAS, M. (2019): Diagnosi 2019. El sensellarisme a Barcelona. Evolució i joves en situació de sensellarisme, Barcelona, Ajuntament de Barcelona, XAPSLL.

DE ROBERTIS, C. (2003): Fundamentos de Trabajo Social. Ética y metodología, Valencia: Nau Libres. 
DELGADO, M. y MALET, D. (2007): “El espacio público como ideología”, Urban Doc., 1, Barcelona, Universitat de Barcelona, Institut Català d'Antropología, p. 57-65.

FEDERACIÓN DE ENTIDADES DE APOYO A PERSONAS SIN HOGAR (2013): Documento marco de la Federación de Entidades de apoyo a las personas sin hogar [Documento marco].

FERRERES, S.; FERNÁNDEZ, G. (2018): “Espai públic i penalització del sensellarisme des d'un enfocament de drets humans", Revista Barcelona i Societat, 22, p. 51-70.

FOURIE C.D. (1993): Un nou acostament al sistema de l'arrendament de la terra de Zulu: Una explicació antropològica històrica del desenvolupament d'un establiment irregular, Rhodes University, Grahamstown, Sudáfrica.

FUNES, J. (2001): “La nova Llei penal i educativa: una lectura en clau educativa i que intenta ser il-lusionada", Educació Social, 18, Barcelona.

GENERALITAT DE CATALUNYA (2020): Plec de prescripcions Tècniques del Contracte de gestió del SASSEP (Serveis d'atenció social al sensellarisme a l'espai Públic), p. 12-13, <https:// contractaciopublica.gencat.cat/ecofin_pscp/ AppJava/notice.pscp?reqCode=viewCn\&idD oc $=68718233$ '.

HARVEY, D. (2003): “The righty to the city", International Journal of Urban and Regional Research, 27.

HOWE, D. (1997): La teoría del vínculo afectivo para la práctica del trabajo social, Barcelona, Paidós.

LEFEBVRE, H. (1969): El derecho a la ciudad, Madrid, Península.

LÓPEZ, O.; SÁEZ, M. (2009): La població RROM immigrant de Romania a Catalunya: Accés i ús dels serveis sanitaris catalans i situació de salut, Barcelona, Departament de Salut de la Generalitat de Catalunya-Universitat Autònoma de Barcelona.

MALDONADO, J. (2008): "El abordaje profesional de la demanda: detección, enfoque y dirección", Documentos de trabajo social: Revista de trabajo y acción social, 43-44, p. 6186.

MATULIČ, M.V. (2015): Procesos de inclusión social de las personas sin hogar en la ciudad de Barcelona: relatos de vida y acompañamiento social, Universitat de Barcelona, en TDX (Tesis Doctorals en Xarxa), <http://www.tesisenred. net/handle/10803/393958 .

MARTÍNEZ, M.; MIRA-PERCEVAL, M. y REDERO, H. (1996): "Administración social: servicios de bienestar social. Coordinación de los servicios sociales", en ALEMÁN, C. y GARCÉS FERRER, J., Administración social: Servicios de Bienestar social, p. 271-300.
MAYA, E. (2008): “Objeto y modo de actuación del trabajador social”. Boletín electrónico Surá, 154, 〈http://www.ts.ucr.ac.cr/binarios/sura/ sura-0154.pdf $\rangle$.

MORATA, T. (2009): “Pedagogía Social Comunitaria: un modelo de intervención socioeducativa integral”, Educación Social. Revista de Intervención Socioeducativa, 57, p. 13-32.

MUÑOZ, M.; VÁZQUEZ, C. y VÁZQUEZ, J.J. (2003): Los límites de la Exclusión. Estudio sobre los factores económicos, psicosociales y de salud que afectan a las personas sin hogar en Madrid, Madrid, Témpora y Caja Madrid.

PALLERES, G. (2004): Derecho a la ciudad: personas sin hogar en la ciudad de Buenos Aires, Quito, Instituto de la ciudad de FLACSO, Consejo Latinoamericano de Ciencias Sociales.

ROCHE, P. (2007): "Les défis de la proximité dans le champ professionnel”, Nouvelle revue de psychologie, Ramonville Sant-Agne, Erès.

ROSSELL, T. (1987): La entrevista en trabajo social, Barcelona, EUGE.

SÁNCHEZ MORALES, M.R. (2010): “Las personas sin hogar en España”, Revista Española de Sociología, 14, p. 21-42.

SOJA, E.W. (1996): Thirdspace: Journeys to Los Angeles and Other Real-and-Imagined Places, Oxford, Blackwel.

SUBIRATS, J. (2010): “Les Polítiques socials a Catalunya: Algunes reflexions en plena transformación social”. Revista de Treball Social (RTS), 191, Barcelona, Colegio Oficial de Diplomados en Trabajo Social y Asistentes Sociales de Cataluña, p. 9-19.

SUBIRATS, J.; ALFAMA, E. y OBRADORS, A. (2009): Ciudadanía e inclusión social frente a las inseguridades contemporáneas. La significación del empleo, Documentos de Trabajo. Fundación Carolina/32.

TAPADA, T. y ARBACI, S. (2011): “Proyectos de regeneración urbana en Barcelona contra la segregación socioespacial (1986-2009): ¿solución o mito?", ACE, Ciudad y entorno, año 6, 17, p. 187-222.

TAYLOR, S.J. y BOGDAN, R. (1996): Introducción a los métodos cualitativos de investigación, Barcelona, Paidós.

TRILLA, C. y VILANOVA, J.M. (2017): “Drets a l'habitatge i polítiques públiques”, en GOMÀ, R. y SUBIRATS, J. (coords.), Canvi d'època i de polítiques publiques a Catalunya, p. 172.

VELÁZQUEZ, F. (2007): Conversaciones sobre el derecho a la ciudad, Bogotá: Fedevivienda. 